\title{
The Influence of Specific Antibody on the Disappearance of Staphylococcal Enterotoxin B from Blood*
}

\author{
Morton I. Rapoport, $\dagger$ Leland F. Hodoval, Earl W. Grogan, Virginia \\ McGann, and William R. Beisel \\ (From the U.S. Army Medical Unit, Walter Reed Army Medical Center, Fort Detrick, Md.)
}

Staphylococcus aureus produces a variety of toxins, enzymes, and metabolites, among which are enterotoxins $\mathrm{A}$ and $\mathrm{B}$, exotoxins associated with certain outbreaks of food poisoning (2). Recent reports have established the lethal nature of enterotoxin $\mathrm{B}$ after its intravenous injection, with death in experimental animals characterized by profound shock (3-5). Fever and several other toxic manifestations of intravenously administered staphylococcal enterotoxin $B$ (SEB) resemble those of bacterial endotoxin (6-10). In view of a possible etiologic relationship of staphylococcal enterotoxin to the shock syndrome of staphylococcal sepsis, there has been surprisingly little investigation of intravenously administered enterotoxin.

The purified toxin produced by Schantz and coworkers (11) has been characterized extensively. It was shown to be a simple protein, free of any detectable lipid or carbohydrate, having a molecular weight of approximately 35,000. Electrophoretic studies revealed its migration as a single component with an isoelectric point of $\mathrm{pH}$ 8.6. Serologic studies by means of the Oudin and Ouchterlony techniques indicated greater than $99 \%$ homogeneity. It will withstand a temperature of $60^{\circ} \mathrm{C}$ for 16 hours without loss of toxicity.

Previous work performed in our laboratory showed that SEB was cleared rapidly from the blood of experimental animals (4). It was observed further that animals surviving an initial challenge appeared to clear $\mathrm{SEB}$ at a somewhat slower rate after a second challenge. In contrast,

\footnotetext{
* Submitted for publication September 28, 1965; accepted May 23, 1966.

A portion of this work appeared in abstract form (1).

In conducting the research described in this report, the investigators adhered to the principles of laboratory animal care as established by the National Society for Medical Research.

$\dagger$ Address requests for reprints to Major Morton I. Rapoport, MC, Walter Reed Army Medical Center, Fort Detrick, Md. 21701.
}

other investigators have shown that the phenomenon of tolerance and immunity to bacterial endotoxins are characterized by increased, rather than delayed, rates of clearance $(12,13)$. In view of certain similarities in the toxic manifestations of these two bacterial products it seemed paradoxical that a degree of immunity might alter their clearance kinetics in opposite directions.

The present report extends observations on the clearance rate of labeled SEB from the circulation of rhesus monkeys and demonstrates the marked alterations in clearance rate produced by acutely administered type specific antitoxins.

\section{Methods}

Animals. Healthy Macaca mulatta (rhesus) weighing 2.5 to $3.5 \mathrm{~kg}$ were placed at least 1 week preceding investigation in restraining chairs 'specially designed to permit study in a nonanesthetized state. These animals had no known previous experience with SEB, and each was used for only a single challenge with this toxin. On the day before study bilateral indwelling saphenous vein catheters were inserted, one to permit injection of the test materials and the second to allow repeated blood sampling.

Labeling and administration of toxin. The highly purified SEB as described by Schantz (11) was isotopically labeled using a modification of the method described by Talmage, Dixon, Bukantz, and Dammin (14) and Clement and McNicol (15). Ten mg of lyophilized toxin was dissolved in a sterile vaccine bottle in $2 \mathrm{ml}$ of phosphate-buffered saline, $\mathrm{pH}$ 7.4. To this solution was added $0.4 \mathrm{ml}$ of a mixture containing $254 \mathrm{mg}$ of iodine $\left(\mathrm{I}_{2}\right)$ and $332 \mathrm{mg}$ of potassium iodide (KI) in $10 \mathrm{ml}$ of distilled water. Finally, $1.0 \mathrm{ml}$ of carrier-free ${ }^{131} \mathrm{I}$ averaging 1.0 mc per $\mathrm{ml}$ was added. The mixture was allowed to react for 30 minutes with occasional agitation. The labeled toxin was then separated from the unbound ${ }^{131}$ I by passing the mixture successively through two columns of Rexyn $201(\mathrm{OH})^{1}$ resin at room temperature. The toxin in the columns was eluted with $\mathrm{pH} 7.4$ phosphate buffer and 2- to 3-ml amounts were collected. This procedure yielded a product that had approximately 20 atoms of ${ }^{131} \mathrm{I}$ per molecule of toxin and less than $1 \%$ un-

\footnotetext{
${ }^{1}$ Fisher Scientific Co., Fairlawn, N. J.
} 
bound ${ }^{131} \mathrm{I}$. The toxicity after this labeling procedure was unchanged.

Challenge with SEB- ${ }^{191} \mathrm{I}$ was accomplished by the intravenous route with a dose of $1 \mathrm{mg}$ per $\mathrm{kg}$ of body weight, which is generally lethal. The specific activity ranged from 5 to $10 \mu \mathrm{c}$ per $\mathrm{mg}$ of toxin.

Preparation of antisera. Equine antiserum was prepared by hyperimmunizing Chincoteague ponies with increasing doses of SEB subcutaneously without adjuvant over a $4 \frac{1}{2}$-month period. Serum was pooled, frozen, and later studied for prophylactic and therapeutic efficacy. Nonimmune control serum was obtained from other Chincoteague ponies and processed in a similar manner. In addition, homologous species antiserum was prepared by hyperimmunizing a group of rhesus monkeys similarly with increasing doses of SEB. Serum from these animals was pooled and frozen.

Radioactivity determinations. Plasma radioactivity was determined, since SEB- ${ }^{181} \mathrm{I}$ localized almost entirely in the plasma with less than $5 \%$ adhering to leukocytes and negligible amounts to red blood cells (4).

Four-ml heparinized blood samples were collected at $1.5,5.5,15,30,60,180,300$, and 420 minutes postchallenge. The blood was centrifuged at $3,000 \mathrm{rpm}$ in a PR-2 International centrifuge for 30 minutes. Plasma was then separated, and radioactivity was determined on a $1-\mathrm{ml}$ sample in a scintillation well counter. An additional $1 \mathrm{ml}$ of plasma was allowed to react with $0.5 \mathrm{ml}$ $30 \%$ trichloroacetic acid (TCA), centrifuged, and the radioactivity of $1 \mathrm{ml}$ of supernatant determined. TCA supernatant hereafter will be referred to as free ${ }^{131} \mathrm{I}$.

Protocols. A series of related experiments was designed to establish the clearance kinetics of SEB- ${ }^{181} \mathrm{I}$, its relationship to the clearance of carrier-free ${ }^{181} \mathrm{I}$, and finally the influence of passively administered type specific antibodies. Protocols depicting the experimental variables are listed in Table I.

Data were plotted on semilogarithmic paper as the per cent of initial plasma radioactivity, with the counts per minute of the 1.5-minute sample assigned a value of 100 . The initial radioactivity recovered in plasma at that time ranged from 80 to $90 \%$ of the injected material based on an assumed blood volume of $7 \%$ of body weight in the rhesus monkey (4).
In an attempt to delineate further the stability of the label, the ${ }^{181} \mathrm{I}$ uptake of the thyroid gland was determined. This measurement was performed in all animals of protocols 1,2 , and 3 (Table I). The animals were sacrificed 7 hours after challenge; thyroid glands were removed and counted in the well counter. Thyroid gland uptake was calculated as the per cent of ${ }^{131} \mathrm{I}$ dose administered.

\section{Results}

Toxicity studies. The prophylactic and therapeutic efficacy of the antiserum of equine origin was determined by one of us in monkeys challenged intravenously with $1 \mathrm{mg}$ per $\mathrm{kg}$ of unlabeled SEB. This dose of toxin was lethal for 11 of 14 control monkeys; in contrast, no deaths occurred in ten monkeys given $5 \mathrm{ml}$ per $\mathrm{kg}$ of antiserum 1 hour before SEB challenge or in eight monkeys treated with a similar volume of antiserum 1 hour after SEB challenge. Thus, the mortality of untreated controls was significantly greater than that in prophylactically protected $(p<0.001)$ or treated $(p<0.001)$ animals.

In vitro studies. In vitro studies were designed to determine the antigenic integrity of the labeled toxin. By means of Ouchterlony agar gel diffusion and immunoelectrophoretic techniques, various preparations of SEB-131I were compared with unlabeled toxin.

Labeled preparations of toxin that were stored up to 4 weeks at $4^{\circ} \mathrm{C}$ had essentially the same serologic activity as the unlabeled preparations. In antigen titrations $0.02 \mu \mathrm{g}$ was the minimal amount of either antigen that formed a visible line of precipitate with antiserum. A modification of the technique of Wright (16) was used to measure antibody-binding capacity. It was found that both labeled and unlabeled toxin had the same

TABLE I

Protocols depicting experimental variables

\begin{tabular}{|c|c|c|c|c|c|c|c|c|c|}
\hline \multirow[b]{2}{*}{ Protocol } & \multirow{2}{*}{$\begin{array}{l}\text { No. of } \\
\text { monkeys }\end{array}$} & \multirow[b]{2}{*}{181 I } & \multirow[b]{2}{*}{ SEB-181 I* } & \multicolumn{2}{|c|}{$\begin{array}{l}\text { Nonimmune } \\
\text { equine serum }\end{array}$} & \multicolumn{2}{|c|}{$\begin{array}{l}\text { SEB immune } \\
\text { equine serum }\end{array}$} & \multicolumn{2}{|c|}{$\begin{array}{c}\text { SEB immune } \\
\text { monkey serum }\end{array}$} \\
\hline & & & & Dose & Time & Dose & Time & Dose & Time \\
\hline \multirow{9}{*}{$\begin{array}{l}1 \\
2 \\
3 \\
4 \\
5 \\
6 \\
7 \\
8\end{array}$} & \multirow{9}{*}{$\begin{array}{l}6 \\
6 \\
6 \\
6 \\
6 \\
6 \\
6 \\
6\end{array}$} & \multirow{3}{*}{$\begin{array}{c}\mu c / k g \\
5\end{array}$} & $m g / k g$ & $\mathrm{ml} / \mathrm{kg}$ & $\min$ & $\mathrm{ml} / \mathrm{kg}$ & $\min$ & $\mathrm{ml} / \mathrm{kg}$ & $\min$ \\
\hline & & & 1 & & & & & & \\
\hline & & & & & & & & & \\
\hline & & & 1 & & & 6 & 30 before & & \\
\hline & & & 1 & & & & & 6 & 30 before \\
\hline & & & 1 & 6 & 30 before & & & & \\
\hline & & 5 & & & & 6 & 30 before & & \\
\hline & & & 1 & & & 6 & 30 after & & \\
\hline & & & 1 & & & 6 & 120 after & & \\
\hline
\end{tabular}

* SEB = staphylococcal enterotoxin B. 
equivalence values. Immunoelectrophoretic studies with $0.02 \mathrm{M}$ borate buffer, $\mathrm{pH} 8.3$, gave additional evidence that the labeling procedure did not alter antibody-binding sites.

Relative potencies of the hyperimmune equine, the nonimmune equine, and the hyperimmune monkey sera were determined by in vitro neutralization (16). The equivalence value of the hyperimmune equine serum was approximately sixfold greater than that of the monkey antiserum. At equivalence, the value for the equine serum was $500 \mu \mathrm{g}$ toxin per $\mathrm{ml}$ serum and for the monkey serum, $80 \mu \mathrm{g}$ toxin per $\mathrm{ml}$ serum. The nonimmune equine serum showed essentially no neutralization of the toxin.

In vivo studies. Six monkeys were given SEB-131 I in a dose of $1 \mathrm{mg}$ per $\mathrm{kg}$ (protocol 1). Disappearance of radioactivity from plasma is shown in Figure 1. Both total plasma and TCAprecipitable radioactivity are shown with the mean

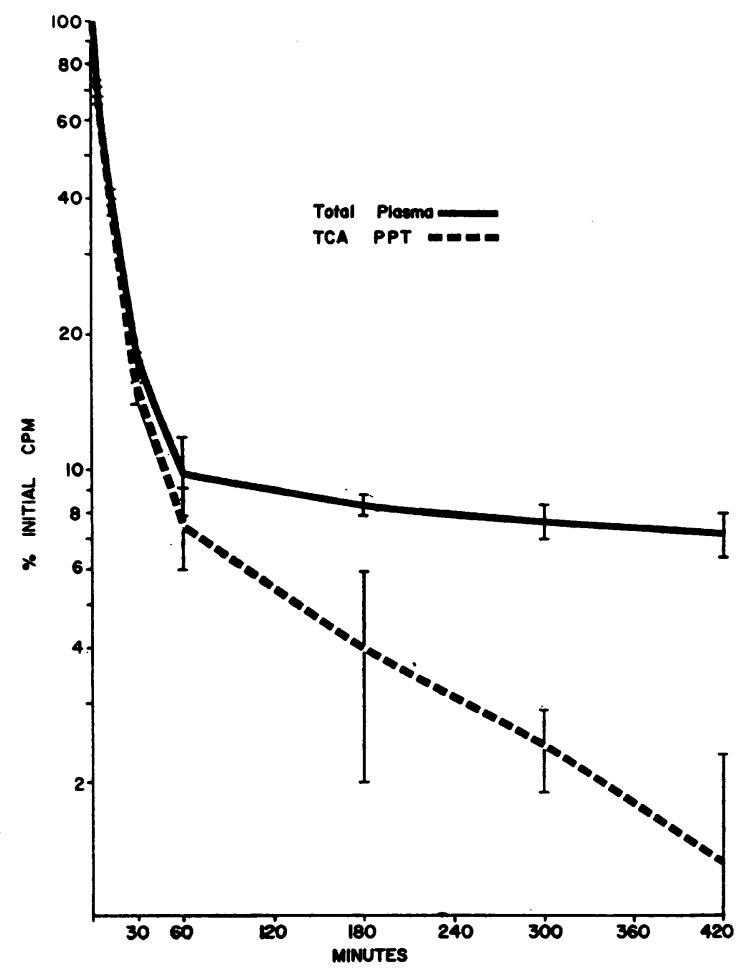

Fig. 1. Disappearance from plasma of SEB- ${ }^{190}$ I in six MONKEYs. The solid line indicates total plasma radioactivity, and the broken line indicates TCA precipitable radioactivity. Data are presented as mean $\pm 2 \mathrm{SE}$. The progressive separation of the two curves is a function of deiodination of the toxin. SEB = staphylococcal enterotoxin $\mathrm{B} ; \mathrm{TCA}=$ trichloroacetic acid.

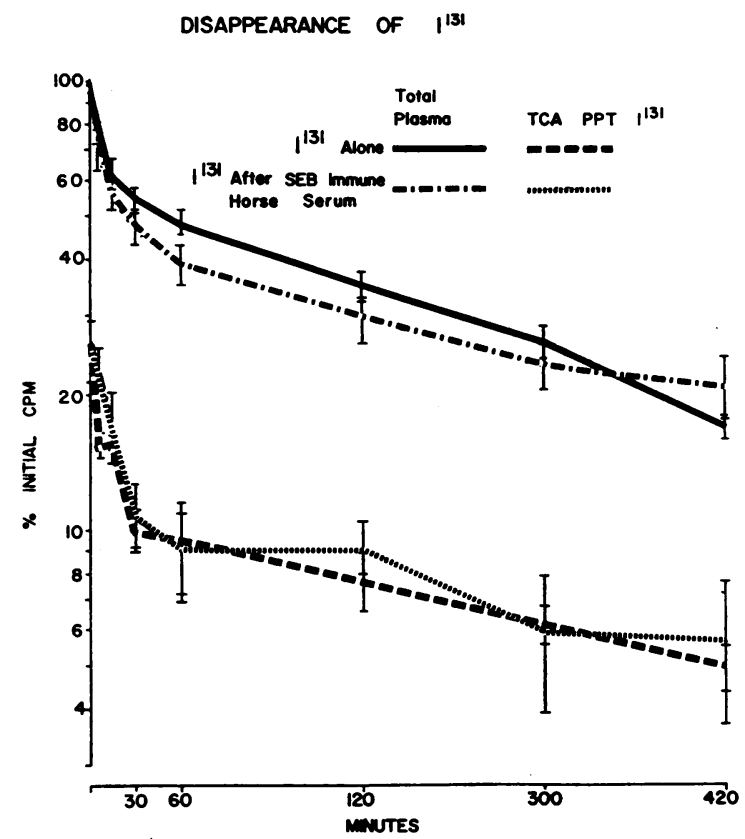

Fig. 2. Disappearance From PLASMa OF CARRIER-FREE ${ }^{131}$ I IN NONIMMUNE MONKEYS AND MONKEYS GIVEN HYPERIMMUNE EQUINE SERUM 30 MINUTES BEFORE CARRIERFREE ${ }^{191} \mathrm{I}$. The upper curves represent total plasma radioactivity and the lower curves, protein-bound radioactivity.

plus or minus $2 \mathrm{SE}$. The progressive separation of the two curves can be ascribed to deiodination of the toxin. The disappearance of protein-bound radioactivity is curvilinear with a prominent initial rapid clearance phase having a mean half disappearance time $\left(t_{1}\right)$ of 8 minutes with a range of 7 to 9 minutes.

The disappearance of carrier-free ${ }^{131} \mathrm{I}$ from the plasma of six monkeys is shown in Figure 2 (protocol 2). The rate of ${ }^{131}$ I removal is considerably more gradual than that of SEB-131I, but far more important is the observation that less than $25 \%$ of the radioactivity is TCA precipitable or protein bound at most sampling times. This finding suggests that the relatively high per cent of protein-bound radioactivity shown in the initial period of Figure 1 represents ${ }^{131} \mathrm{I}$ still bound to toxin rather than ${ }^{131} \mathrm{I}$ bound to serum proteins.

Figure 3 indicates a profound delay in SEB disappearance produced by prophylactic administration of equine antiserum 30 minutes before SEB. In contrast to the rapid clearance of SEB${ }^{131}$ I shown in Figure 1, the disappearance curve after equine antiserum prophylaxis had a $t_{1}$ of 6 hours and was only minimally curvilinear. The 
INFLUENCE OF IMMUNE HORSE

SERUM ON DISAPPEARANCE

OF SEB $-1^{|3|}$

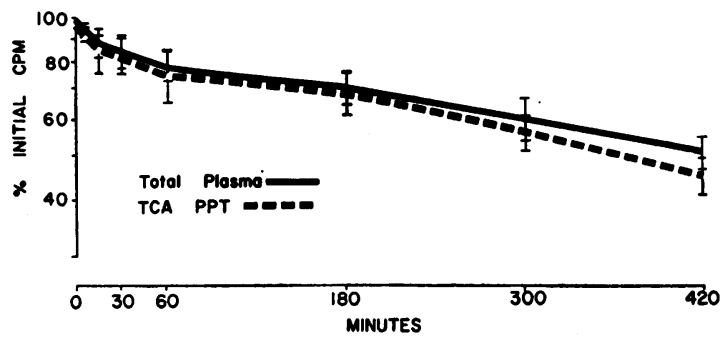

Fig. 3. Disappearance from Plasma of SEB-- ${ }^{181}$ I in MONKEYS GIVEN HYPERIMMUNE EQUINE SERUM 30 MINUTES BEFORE CHALLENGE. Solid and broken lines indicate total and TCA-precipitable radioactivity, respectively. There is a marked delay in disappearance of radioactivity as well as a reduction in the degree of deiodination of the toxin.

rate of deiodination, indicated by a separation of the two curves, was also delayed.

A homologous species antiserum was studied for its effect on SEB disappearance. Serum obtained from monkeys immunized over a 2 -month period with SEB was given in a dose of $6 \mathrm{ml}$ per $\mathrm{kg}$ to a group of monkeys 30 minutes before SEB, as shown in Figure 4 (protocol 4). A delay in clearance of SEB as well as in the deiodination of

INFLUENCE OF IMMUNE MONKEY SERUM ON DISAPPEARANCE OF SEB- $|3|$

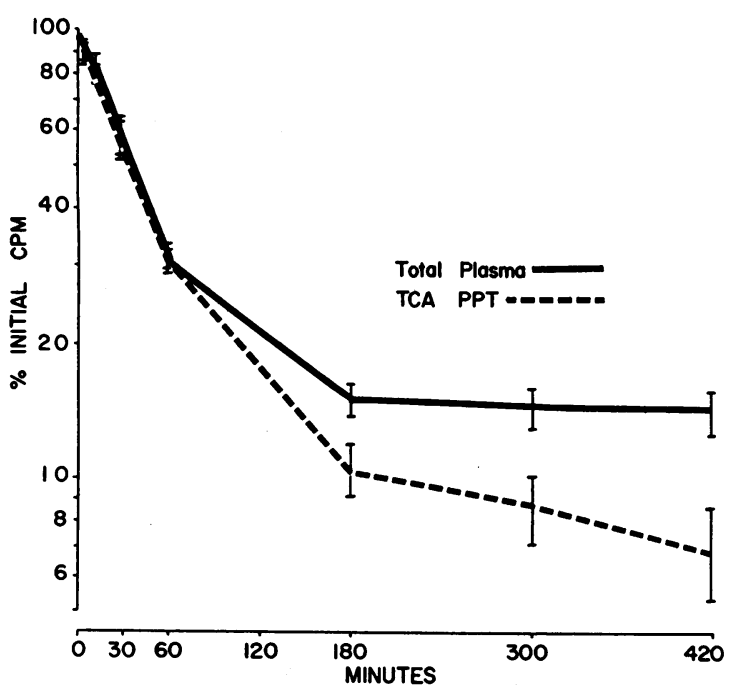

Fig. 4. INFLUENCE OF HOMOLOGOUS SPECIES ANTISERUM PROPHYLAXIS AND CLEARANCE OF SEB- ${ }^{181}$ I FROM PLASMA Designations are as in earlier Figures. the labeled toxin was demonstrated, although less prominent than that seen with equine antitoxin. The $t_{1}$ of the initial disappearance phase was 45 minutes with a range of 40 to 55 .

Figure 5 (protocol 5 ) indicates control studies relative to the alterations in SEB clearance produced by equine immune sera. Nonimmune equine serum given to monkeys 30 minutes before SEB had had no influence on either the initial rapid clearance phase or deiodination of the

\section{INFLUENCE OF NON-IMMUNE HORSE SERIM ON}

THE OISAPPEARANCE OF SEB-1131

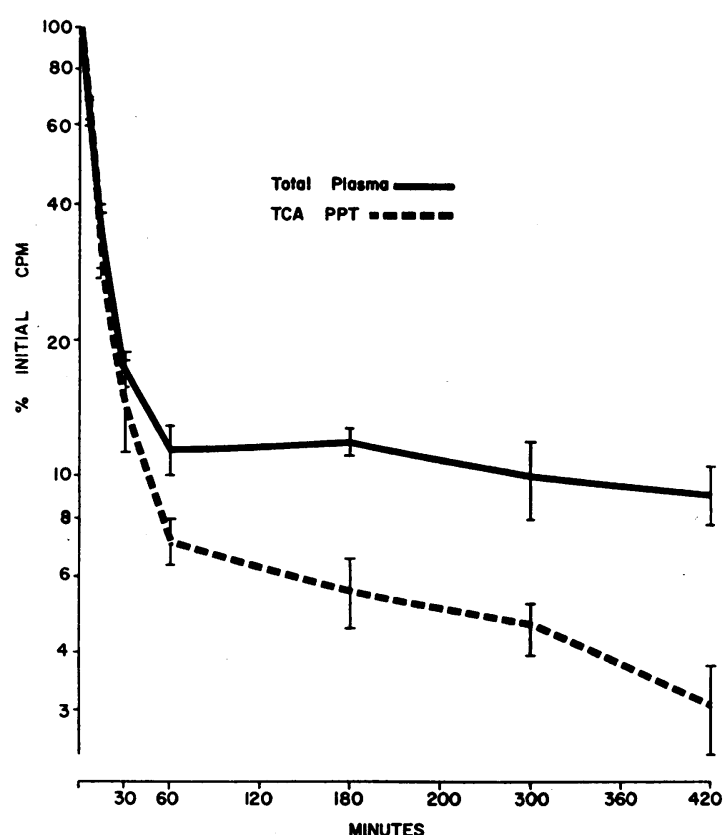

Fig. 5. Disappearance of SEB- ${ }^{181}$ I FROM Plasma of MONKEYS GIVEN CONTROL NONIMMUNE EQUINE SERUM 30 MINUTES BEFORE TOXIN. No effect on disappearance was observed with this control serum.

toxin. The implication from this study was that normal control equine serum per se was not responsible for the delay in SEB disappearance seen after antibody-containing equine serum. Furthermore, SEB immune equine serum (protocol 6) failed to alter the clearance of carrier-free ${ }^{131} \mathrm{I}$ (Figure 2), an indication that this serum does not bind or interact with the ${ }^{131} \mathrm{I}$ label itself.

The two immune sera and the nonimmune equine serum given before SEB-131I are compared with the control clearance of SEB-131I in Figure 6. Only TCA precipitable radioactivity is plotted. 
The finding that immune monkey serum had less influence on SEB disappearance than immune horse serum was not unexpected in view of the in vitro experiments previously reported. It had been shown by means of in vitro neutralization tests that the hyperimmune equine serum was six times more potent than the hyperimmune monkey serum.

In view of the ability of SEB immune sera given prophylactically to prolong clearance of SEB-131 ${ }^{13}$,

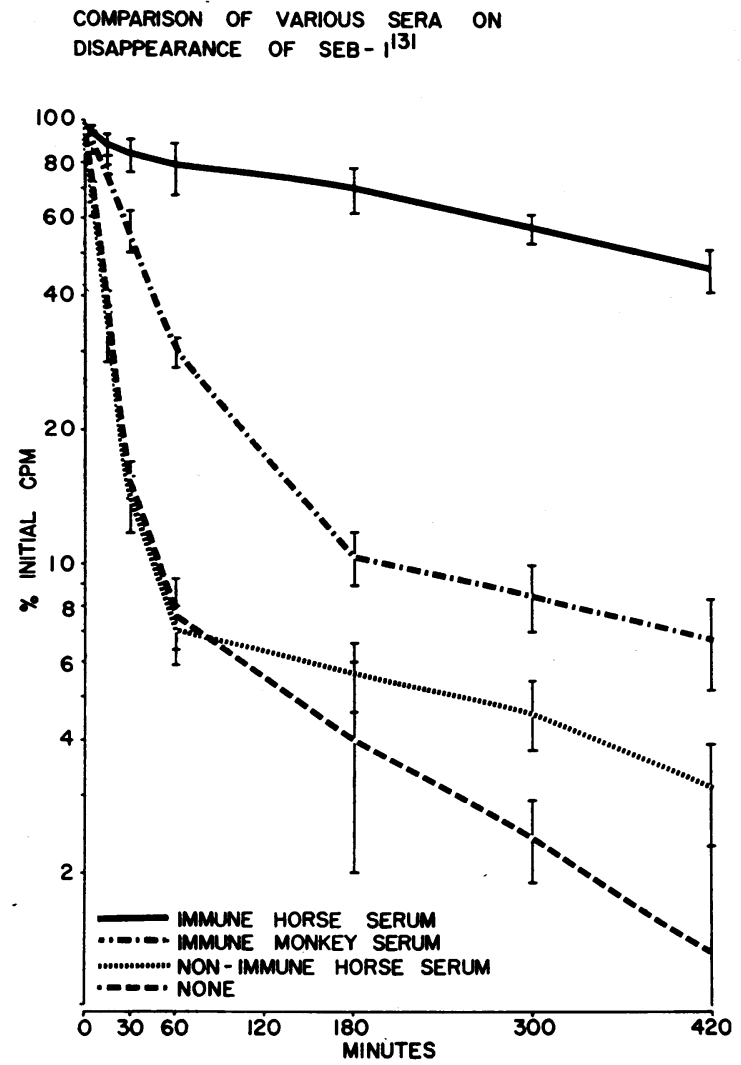

Fig. 6. A COMPOSITE FIGURE SHOWING EFFECT ON SEB- ${ }^{131}$ I CLEARANCE PRODUCED BY VARIOUS SERA GIVEN PROPHYLACTICALLY. Only protein-bound radioactivity is plotted.

it seemed apparent that a specific binding relationship might be the mechanism for this delay. Studies were performed to investigate further this possible binding phenomenon. Immune equine antiserum was given in a dose of $6 \mathrm{ml}$ per $\mathrm{kg}$ to six monkeys 30 minutes after and to six monkeys 120 minutes after SEB-131I (protocols 7 and 8). In both situations (Figures 7 and 8), disappearance of the toxin progressed in the expected fashion
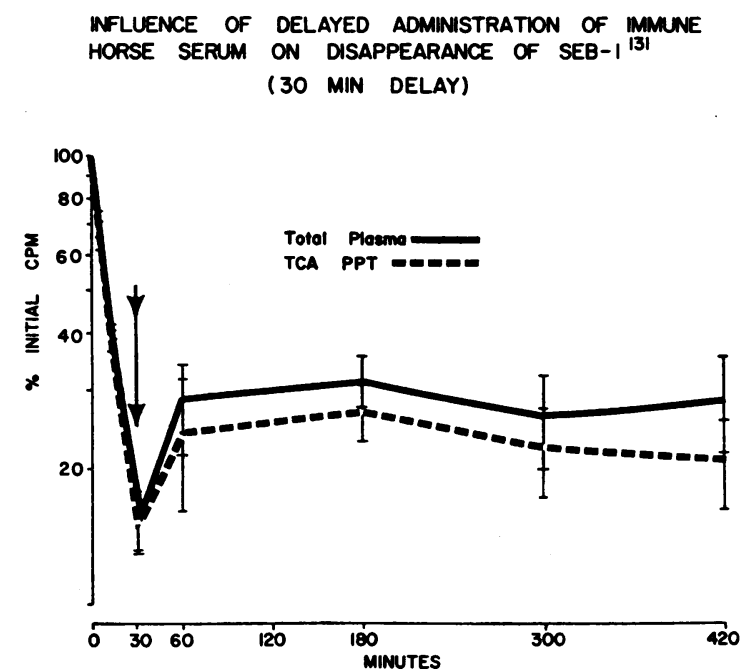

Fig. 7. Reappearance of PLASMa Radioactivity PRODUCED BY ADMINISTRATION OF IMMUNE EQUINE ANTISERUM 30 MINUTES AFTER TOXIN.

until the moment of antiserum administration, when a prompt reversal of disappearance was apparent, with reappearance of radioactivity in the circulation. This radioactivity appears to represent primarily, if not exclusively, immunoactive toxin. This study would imply that despite rapid clearance of SEB-131I from the circulation, a portion of this material could be removed from the sites of localization in a reversible fashion.

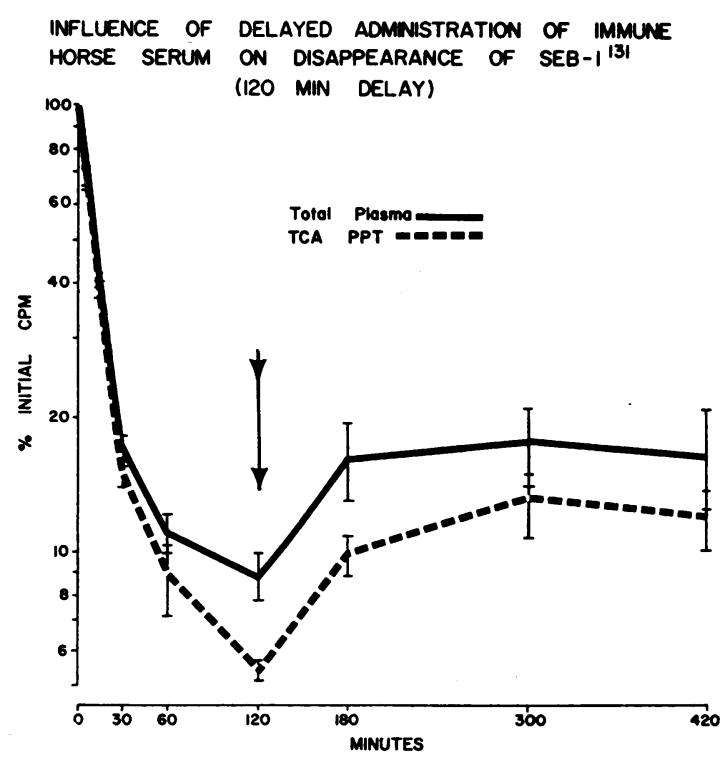

Fig. 8. Reappearance OF PLASMa Radioactivity AS A RESULT OF 120 MINUTES DELAY IN ANTISERUM ADMINISTRATION. 
Finally, the integrity of the radioactive label was further confirmed by determining thyroid uptake in the animals studied. The 7-hour uptake in monkeys given carrier-free ${ }^{131}$ I ranged from 4 to $7 \%$. In contrast, thyroid uptakes were constantly below $1.0 \%$ in monkeys given SEB-131I only and below $0.6 \%$ in monkeys given immune serum before SEB-131. The latter findings would be best explained by a reduced amount of available free ${ }^{131} \mathrm{I}$ in animals given the labeled toxin.

\section{Discussion}

In performing in vivo studies with isotopically labeled material it would be erroneous to assume that all detected radioactivity reflected the original material. It is obvious that certain labeled substances are quickly altered or dissociated so that the radioisotope no longer reflects the molecule being studied. Iio and Wagner (17) observed that dogs given ${ }^{131}$ I-labeled aggregated albumin had a relatively rapid clearance rate, but within $12 \mathrm{~min}$ utes after injection there was a progressive return of radioactivity. Subsequent determinations of protein-bound and free ${ }^{131} \mathrm{I}$ showed that the secondary rise in radioactivity was due entirely to free ${ }^{131} \mathrm{I}$. This was interpreted to represent deiodination of the albumin and subsequent recirculation of the free radioisotope. A similar concept was employed during our determinations of SEB label stability. Deiodination appeared minimal in the early rapid phase of SEB clearance. During the initial 30 minutes, free ${ }^{131} \mathrm{I}$ represented less than $15 \%$ of the circulating radioactivity, a time that encompassed four $t_{\frac{1}{2}}$ periods of the labeled toxin.

In addition, thyroid uptake of radioiodine was markedly reduced in animals given SEB- ${ }^{131} I$ when compared with those given carrier-free ${ }^{131} \mathrm{I}$. This finding could be explained by a reduction in available free ${ }^{131} \mathrm{I}$ in the toxin-challenged group, although actual toxicity to the trapping mechanism might have been an alternate or additional factor in reduced thyroid uptake after SEB.

The mode of removal of SEB from the circulation has not been clearly defined. Similarities in the toxic manifestations of bacterial endotoxin and SEB have been noted by several investigators. These include pyrogenicity, increases in circulating catecholamines, leukopenia followed by leukocytosis, thrombocytopenia, and shock $(4-6,9)$.
Repeated observations by other investigators have shown that the phenomenon of tolerance and the ability to detoxify bacterial lipopolysaccharide substances are functions of the rapidity with which these substances are cleared from the circulation (12, 13, 18, 19). Carey, Braude, and Zalesky (13) showed an increased rate of endotoxin clearance in rabbits with high titers of circulating antibody. Tolerant animals also cleared massive doses of labeled endotoxin at a greater rate than nontolerant animals. Chedid, Boyer, Pophillat, and Parant (19) demonstrated a greater rate of endotoxin clearance from the circulation of tolerant mice.

Perreault and co-workers (20) reported that rabbits given immune serum have an increased endotoxin clearance rate; they concluded that serum antibodies facilitated uptake of endotoxin by reticuloendothelial cells. Jenkin and Rowley (21) noted that mice cleared endotoxin from circulation at an increased rate after it had been pretreated with specific rabbit antiserum.

Furthermore, other investigators have observed a reduction in clearance rate of bacterial endotoxin after reticuloendothelial blockade (12, $22)$. These and other findings implicate the reticuloendothelial system as a major factor in removal of bacterial endotoxins from the circulation.

Sugiyama, McKissic, and Bergdoll (8) reported that Thorotrast markedly increased the sensitivity of young rhesus monkeys to the emetic effect of SEB. They conjectured that the reticuloendothelial system, the major area of endotoxin removal from the circulation, might also be the primary site in the removal of SEB.

We have observed, in rhesus monkeys challenged with a lethal dose of $\mathrm{SEB}$, a relatively rapid rate of clearance from the blood. In direct contrast to the findings of heightened clearance associated with immunity and tolerance to bacterial endotoxin, a marked delay in clearance of SEB occurs when animals are given protective antibody before challenge. If the reticuloendothelial system were the major organ of clearance in the unimmunized animal, type specific antiserum against SEB might be expected to speed rather than delay its clearance from the circulation.

Immune sera prepared from two animal species were capable of significantly inhibiting clearance of the toxin from blood. The fact that equine 
antiserum effected a significantly greater delay than did monkey serum was not unexpected since in vitro neutralization data and hemagglutination inhibition studies both indicated that the immune equine serum had significantly higher titers than did the immune monkey serum preparation. Implicit in this interpretation is the suggestion that ability of the serum preparations to delay clearance of the toxin was related to the ability of the serum to react in the customary in vitro techniques.

The inhibition in SEB clearance produced by antitoxin is not without precedent if one postulates that antibodies may behave as binding proteins. Slaunwhite, Lockie, Back, and Sandberg (23) observed in mice that the action of cortisol and its clearance were adversely influenced by prior administration of its binding protein, transcortin. Other investigators have postulated that the delay in cortisol clearance in pregnancy and other hyperestrogenic states was due to increased protein binding, since transcortin is elevated in these states (24-26).

The delay in enterotoxin clearance produced by prior administration of antitoxin, in addition to the observation that antitoxin after challenge caused a reappearance of toxin in the circulation, tends to exclude the reticuloendothelial system as a major factor in SEB removal. It is doubtful that a toxic substance initially phagocytized by reticuloendothelial cells would be released unchanged from an intracellular location after the administration of the type specific antiserum.

The rapid clearance of toxin from the circulation suggests that it is bound to numerous yet unidentified sites. The administration of antiserum seems to reverse this binding phenomenon to a degree, so that antitoxin-toxin conglomerates are returned to the circulation. This would imply that the binding of toxin to these undefined tissue sites is relatively loose and that its adherence to antitoxin is considerably stronger.

The theorized relationship between toxin and binding sites may best be shown in the following equation : toxin + tissue sites $\stackrel{\mathbf{k}}{\rightleftharpoons}$ toxin-tissue sites.

The addition of antibody (ab) with a binding affinity for toxin greater than the binding affinity of tissue sites results in a new equilibrium: toxin$\mathrm{ab} \stackrel{\mathrm{K}}{\rightleftharpoons} \mathrm{ab}+$ toxin + tissue sites $\stackrel{\mathrm{k}}{\rightleftharpoons}$ toxin-tissue sites.

Perhaps such a mechanism explains the benefit derived by antitoxin administration late in the course of other bacterial exotoxemias. It is conceivable that reversal of well established botulinum toxemia and other exotoxemias might result from competitive binding by the antitoxin. In such instances, it may be postulated that binding of toxin to various tissue sites is reversed, as is its toxicity. Koenig, Spickard, Cardella, and Rogers (27) observed that several patients with type $\mathrm{E}$ botulism had a dramatic reversal of neurologic symptoms after specific antitoxin therapy. They suggested that the toxin might be reversibly bound to tissues and the affinity for antitoxin was greater than tissue sites. Our studies would imply that antitoxin to SEB operates in this fashion.

If the shock syndrome occasionally associated with staphylococcal sepsis is in part due to a massive release of enterotoxin, then it may be further speculated that the appropriate antitoxin might be of therapeutic value.

\section{Summary}

Intravenously administered staphylococcal enterotoxin B (SEB), a simple protein devoid of carbohydrate and lipid, is lethal in small quantities in monkeys.

The disappearance of SEB from the plasma is rapid in nonimmunized monkeys but is markedly prolonged in the presence of immunity against the toxin. Furthermore, therapeutic administration of antiserum reverses the disappearance of SEB and actually returns immunoactive toxin to the circulation. Death after SEB is also prevented by delayed or prophylactic antiserum therapy.

It is conceivable that SEB becomes bound to various tissue sites where it exerts toxic effects, whereas the introduction of antiserum that seems to have a stronger binding affinity serves to remove SEB from tissue sites and is therapeutic in this manner. The implied reversible binding phenomenon between SEB and its antitoxin may explain the mechanism by which the delayed administration of specific antitoxin is beneficial in other exotoxemias.

\section{Acknowledgments}

We acknowledge with pleasure the invaluable help of Maj. H. G. Dangerfield, MC, Lt. E. L. Morris, VC, Lt. D. G. VanOrmer, MSC, Mrs. P. W. Summers, and Mrs. B. J. Eader. 


\section{References}

1. Rapoport, M. I., L. F. Hodoval, E. L. Morris, and W. R. Beisel. Disappearance of staphylococcal enterotoxin in non-immunized and passively immunized monkeys. Clin. Res. 1965, 13, 298.

2. Casman, E. P., M. S. Bergdoll, and J. Robinson. Designation of staphylococcal enterotoxins. J. Bact. 1963, 85, 715.

3. Hayama, T., and H. Sugiyama. Diarrhea in cecectomized rabbits induced by staphylococcal enterotoxin. Proc. Soc. exp. Biol. (N. Y.) 1964, 117, 115.

4. Crawley, G. J., I. Gray, W. A. LeBlang, and J. W. Blanchard. Blood binding, distribution and excretion of staphylococcal enterotoxin in monkeys. J. infect. Dis. 1966, 116, 48.

5. Stolmakova, A. I. Mechanism of the action of staphylococcus enterotoxin on the animal body. 2 . The effect of staphylococcus enterotoxin on circulation. Bull. exp. Biol. Med. 1957, 44 (11), 1345.

6. Clark, W. G., and H. L. Borison. Pyrogenic effect of purified staphylococcal enterotoxin. J. Pharmacol. exp. Ther. 1963, 142, 237.

7. Sugiyama, H., M. S. Bergdoll, and G. M. Dack. Early development of a temporary resistance to the emetic action of staphylococcal enterotoxin. J. infect. Dis. 1962, 111, 233.

8. Sugiyama, H., E. M. McKissic, Jr., and M. S. Bergdoll. Sensitivity of Thorotrast-treated monkeys to staphylococcal enterotoxin. Proc. Soc. exp. Biol. (N. Y.) $1963,113,468$.

9. Sugiyama, H., E. M. McKissic, Jr., and T. Hayama. Hyperfibrinogenemia and thrombocytopenia after staphylococcal enterotoxin. Proc. Soc. exp. Biol. (N. Y.) 1964, 117, 726.

10. Sugiyama, H., E. M. McKissic, Jr., M. S. Bergdoll, and B. Heller. Enhancement of bacterial endotoxin lethality by staphylococcal enterotoxin. J. infect. Dis. 1964, 114, 111.

11. Schantz, E. J., W. G. Roessler, J. Wagman, L. Spero, D. A. Dunnery, and M. S. Bergdoll. Purification of staphylococcal enterotoxin B. Biochemistry 1965, 4, 1011.

12. Beeson, P. B. Tolerance to bacterial pyrogens. II. Role of the reticulo-endothelial system. J. exp. Med. 1947, 86, 39.

13. Carey, F. J., A. I. Braude, and M. Zalesky. Studies with radioactive endotoxin. III. The effect of tolerance on the distribution of radioactivity after intravenous injection of Escherichia coli endotoxin labeled with $\mathrm{Cr}^{51}$. J. clin. Invest. 1958, 37, 441.

14. Talmage, D. W., F. J. Dixon, S. C. Bukantz, and G. J. Dammin. Antigen elimination from the blood as an early manifestation of the immune response. J. Immunol. 1951, 67, 243.

15. Clement, W. E., and G. P. McNicol. The preparation and use of ${ }^{131} I$-tagged fibrinogen to demonstrate fibrinolysis. J. clin. Path. 1959, 12, 544.

16. Wright, S. T. C. A quantitative serum-agar technique. Nature (Lond.) 1959, 183, 1282.

17. Iio, M., and H. N. Wagner, Jr. Studies of the reticuloendothelial system (RES). I. Measurement of the phagocytic capacity of the RES in man and dog. J. clin. Invest. 1963, 42, 417.

18. Herring, W. B., J. C. Herion, R. I. Walker, and J. G. Palmer. Distribution and clearance of circulating endotoxin. J. clin. Invest. 1963, 42, 79.

19. Chedid, L., F. Boyer, F. Pophillat, and M. Parant. Etude de la toxicité d'une endotoxine radioactive $\left({ }^{51} \mathrm{Cr}\right)$ injectée a des parabiontes normaux et hypophysectomisés. Ann. Inst. Pasteur 1963, 104, 197.

20. Perreault, M., F. B. Schweinburg, S. Levenson, J. Israel, and J. Fine. Effect of immune serum on hemorrhagic shock and on metabolism of endotoxemia by the R.E. system. Proc. Soc. exp. Biol. (N. Y.) $1961,108,479$.

21. Jenkin, C. R., and D. Rowley. The role of opsonins in the clearance of living and inert particles by cells of the reticuloendothelial system. J. exp. Med. 1961, 114, 363.

22. Rowley, D., J. G. Howard, and C. R. Jenkin. The fate of ${ }^{32} \mathrm{P}$-labelled bacterial lipopolysaccharide in laboratory animals. Lancet 1956, 1, 366.

23. Slaunwhite, W. R., Jr., G. N. Lockie, N. Back, and A. A. Sandberg. Inactivity in vivo of transcortinbound cortisol. Science 1962, 135, 1062.

24. Mills, I. H., H. P. Schedl, P. S. Chen, Jr., and F. C. Bartter. The effect of estrogen administration on the metabolism and protein binding of hydrocortisone. J. clin. Endocr. 1960, 20, 515.

25. Peterson, R. E., G. Nokes, P. S. Chen, Jr., and R. L. Black. Estrogens and adrenocortical function in man. J. clin. Endocr. 1960, 20, 495.

26. Beisel, W. R., V. C. DiRaimando, and P. H. Forsham. Cortisol transport and disappearance. Ann. intern. Med. 1964, 60, 641.

27. Koenig, M. G., A. Spickard, M. A. Cardella, and D. E. Rogers. Clinical and laboratory observations on type $\mathrm{E}$ botulism in man. Medicine (Baltimore) $1964,43,517$. 